\title{
Experiment on Conical Pick Cutting Rock Material Assisted with Front and Rear Water Jet
}

\author{
Xiaohui Liu, ${ }^{1,2}$ Songyong Liu, ${ }^{1,2}$ Lie Li, ${ }^{1,2}$ and Xinxia Cui ${ }^{1,2}$ \\ ${ }^{1}$ School of Mechatronic Engineering, China University of Mining and Technology, Xuzhou 221116, China \\ ${ }^{2}$ Jiangsu Key Laboratory of Mine Mechanical and Electrical Equipment, China University of Mining and Technology, \\ Xuzhou 221116, China \\ Correspondence should be addressed to Songyong Liu; lsycumt@163.com
}

Received 18 June 2015; Accepted 2 August 2015

Academic Editor: Luigi Nicolais

Copyright (c) 2015 Xiaohui Liu et al. This is an open access article distributed under the Creative Commons Attribution License, which permits unrestricted use, distribution, and reproduction in any medium, provided the original work is properly cited.

Conical picks are one kind of cutting tools widely used in engineering machinery. In the process of rock breaking, the conical pick bears great cutting force and wear. To solve the problem, a new method, conical pick assisted with high pressure water jet, could break rock effectively, and four different configuration modes of water jet were presented. In this paper, based on the analysis of the different water jet configuration's advantages and disadvantages, experiments on front water jet, new typed rear water jet, and the combination of those two water jet configuration modes were conducted to study the assisting cutting performance and obtain the quantitative results.

\section{Introduction}

Conical picks, one kind of cutting tools, are widely used in engineering machinery. Their low cutting efficiency results from impacting with stiff rock directly in the cutting and drilling progress. In most cases, the compressive strength of rock is over $40 \mathrm{MPa}$, which increases the resistant force on pick and results in failure (Figure 1) and low cutting efficiency of pick. Thus, it is significant to find a method to reduce the failure of picks and enhance the efficiency of rock breaking. How to reduce the resistance of rock to the pick must be taken into consideration. Many studies have been conducted on researching the cutting force and even the forces in three orthogonal directions.

Dominant rock properties affecting the performance of picks load were studied, which emphasized that uniaxial compressive strength among the rock properties investigated is best correlated with the measured cutter performance values [1]. Cutting tests were carried out on an established cutting test bed to analyze the relationship between cutting force and coal compressive strength, the carbide tip diameter, and the cutting depth. The results show that the cutting force is linearly related to the compressive strength and exponentially related to both the carbide tip diameter and the cutting depth [2]. Interference mathematical models of straight and revolving cutting were established according to coal cutting theory and carried out coal cutting experiments with different cutting angles, head face radii of pick body, and cutting depths to verify the mathematical model [3]. The cutting forces were researched under varying cutting geometries by means of a semiempirical approach and developed prediction equations of the peak cutting force and mean cutting force shown to be statistically significant by the regression analysis through analyzing the full-scale rock cutting test data [4]. Tool forces were numerically predicted from cutting tests in PFC 3D. Moreover, the peak cutting forces were calculated by utilizing the theoretical equations and the results of experimental studies were given as well. It was pointed out that there is a strong correlation between the modeling, experimental, and theoretical studies [5]. Numerical model of rock cutting processes with road header picks was presented, which is typical for underground excavation and tested the cutting (tangential), normal, and side components forces. Moreover, the results of the 2D and 3D analyses have been compared with one another, and numerical results have been compared with the available experimental data [6]. Permeable quartzose sandstone was subjected to full-scale cutting tests under a chisel-type drag pick in both dry and 


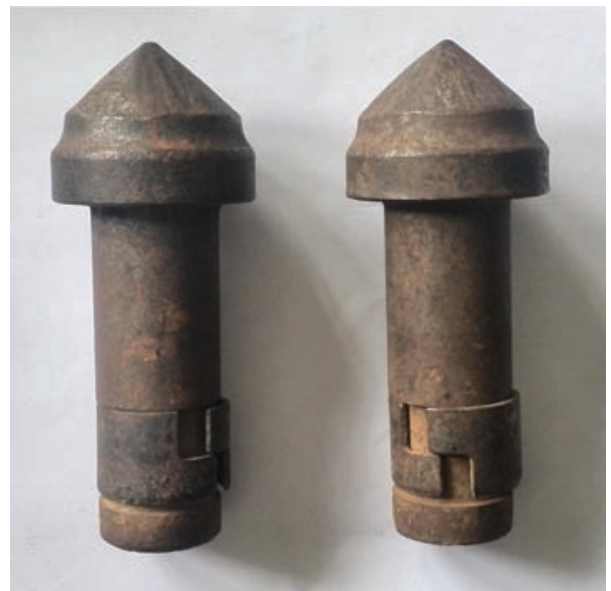

(a) Picks used on road header

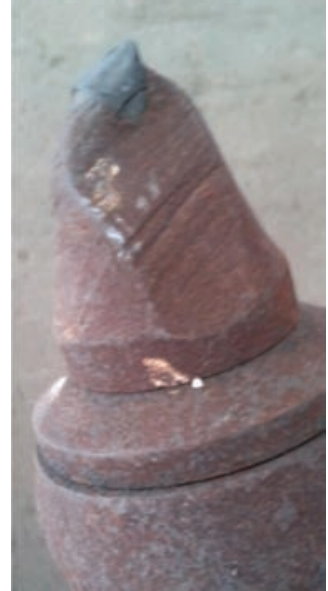

Figure 1: Picks out of work.
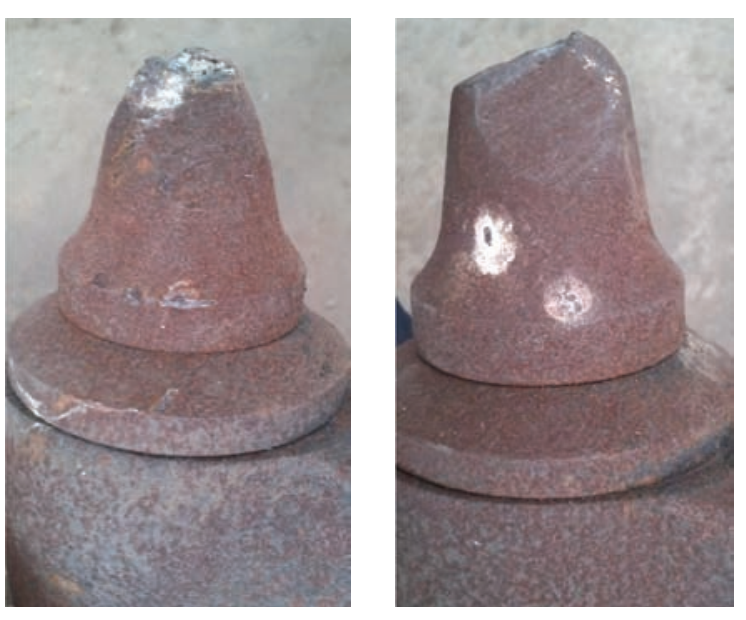

(b) Picks used on shearer . 

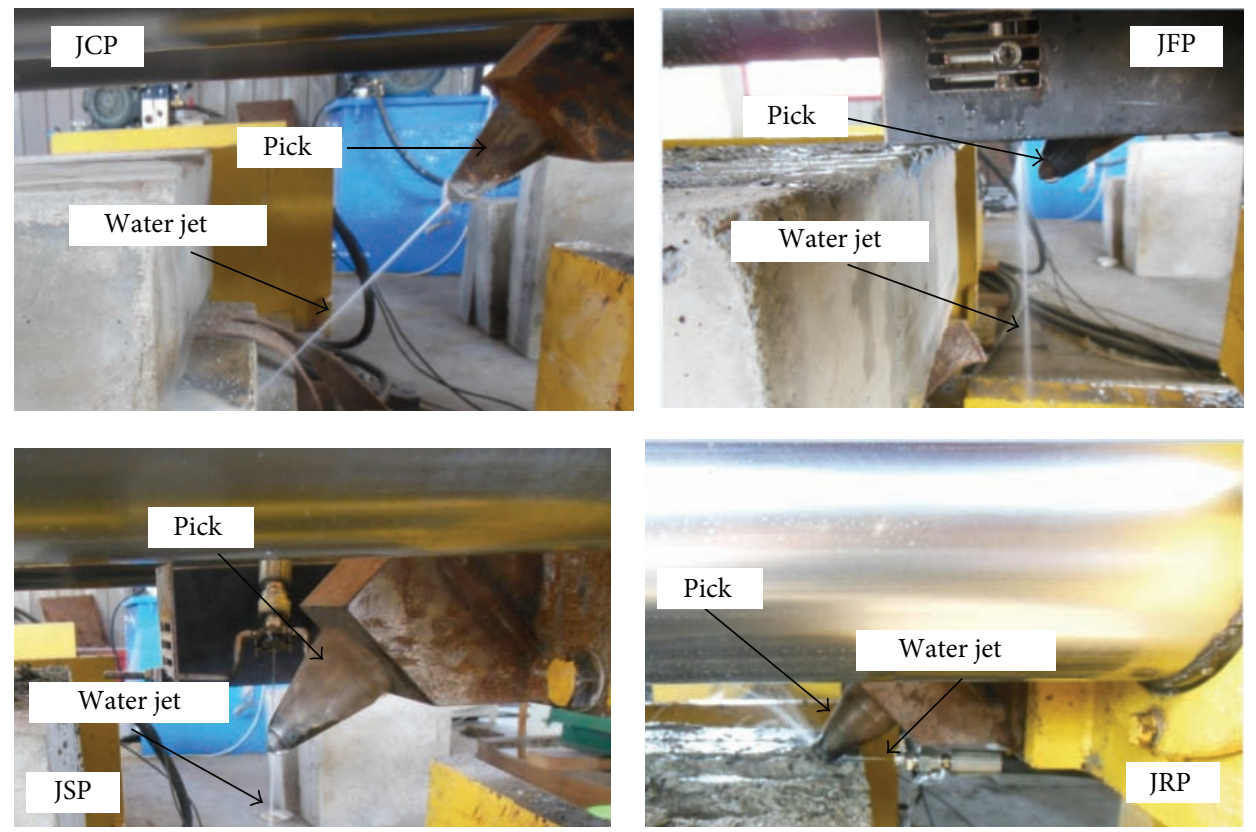

FIGURE 2: Different configuration modes of water jet.
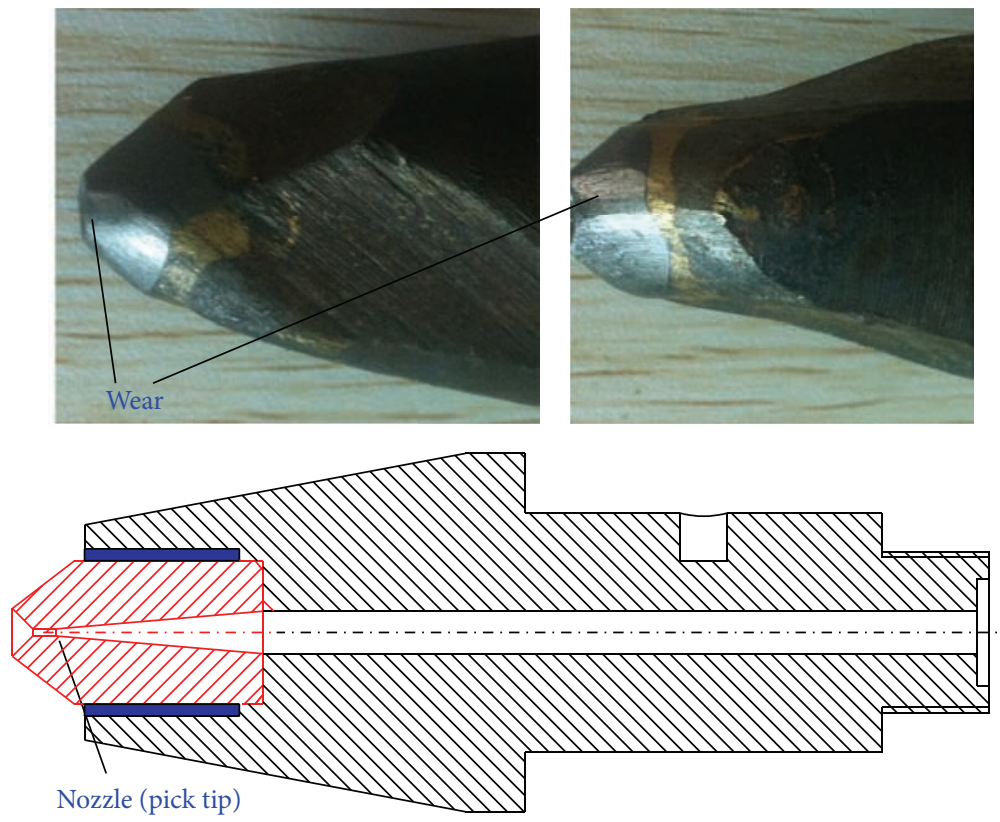

FIGURE 3: Wear of conical pick.

Therefore, based on the analysis of the different water jet configuration's advantages and disadvantages, this paper selects the appropriate jet configuration (JFP, new typed JRP, and the combination one) to conduct the rock breaking experiment to obtain the quantitative results. In the evaluation of rock breaking performance assisted with high pressure water jet, the load fluctuation is included.

\section{Experiment Methods}

The test bed of rock breaking assisted with high pressure water jet is shown in Figure 4. High pressure oil pump provides power for the clamping cylinder and thrust cylinder. High pressure water pump provides water for the nozzle. The rock sample was clamped on the test bench by clamping cylinder 14 . Rock slide 11 can reduce the friction between the rock samples and the test platform, which can conveniently load and move the rock. Pushing cylinder 15 can realize a linear reciprocated cutting action propelling along rail 10 . The displacement sensor is used to record the pick's displacement. The pressure sensor is used to monitor and increase the oil pressure to obtain the cutting force.

When designing the pick, the problems such as the determination of cutting angle and the fixing of the nozzle 


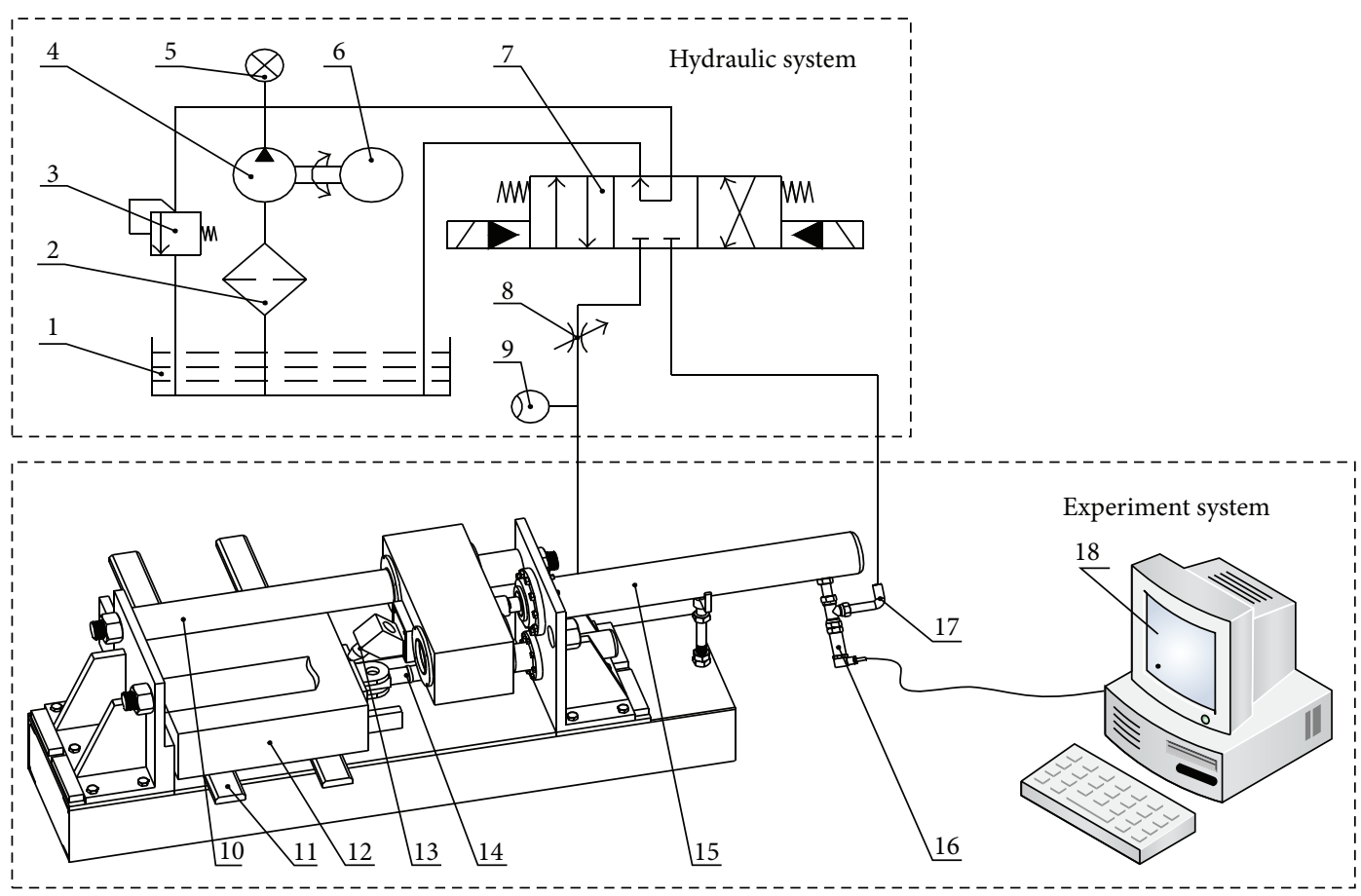
(1) Oil tank
(10) Pushing guide rails
(2) Oil filter
(11) Slideway
(3) Relief valve
(12) Rock sample
(4) Pump
(13) Cutter
(5) Manometer
(14) Clamping cylinder
(6) Motor
(15) Pushing cylinder
(7) Solenoid directional valve
(16) Pressure transducer
(8) Speed control valve
(17) Inlet pipe
(9) Flowmeter
(18) Computer

FIgURE 4: The test bed assisted with high pressure water jet.

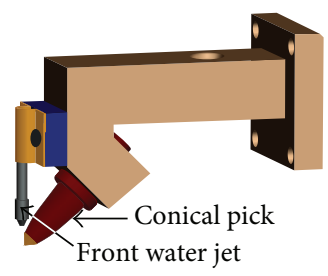

(a) JFP

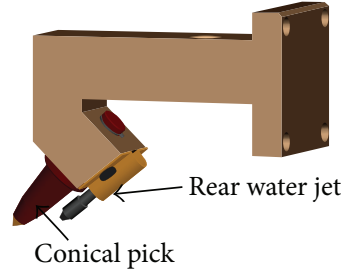

(b) JRP

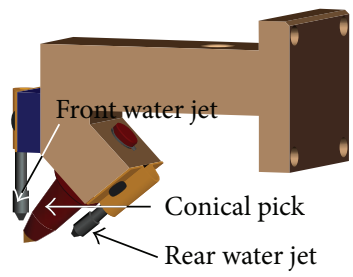

(c) Combined

Figure 5: Different configuration modes.

should be considered. The cutting angle refers to the acute angle between the pick center line and pick velocity direction. The cutting angle of the pick has a great effect on the rock breaking performance. If the cutting angle is too small, the pressure piece cannot be fully effective. If the angle is too big, the pick tip extrudes the rock severely, which causes a lot of dust and makes the pick wears quickly. Researches show that when the cutting angle is about $45^{\circ}$, the energy consumption is low. Therefore, $45^{\circ}$ is chosen as the cutting angle. Different configuration modes are designed, shown in Figure 5. The nozzle diameter is $1 \mathrm{~mm}$.

Cement, sand, and gypsum are used to configure the rock sample in experiments [26]. The external dimension is
TABLE 1: Parameters of rock.

\begin{tabular}{lcccc}
\hline Material & $\begin{array}{c}\text { Density } \\
\left(\mathrm{kg} / \mathrm{m}^{3}\right)\end{array}$ & $\begin{array}{c}\text { Elasticity } \\
\text { modulus } \\
(\mathrm{GPa})\end{array}$ & $\begin{array}{c}\text { Poisson's } \\
\text { ratio }\end{array}$ & $\begin{array}{c}\text { Compressive } \\
\text { strength } \\
(\mathrm{MPa})\end{array}$ \\
\hline $\begin{array}{l}\text { Coal } \\
\text { sample }\end{array}$ & 2378 & 30.12 & 0.27 & 12.36 \\
\hline
\end{tabular}

$600 \times 400 \times 160 \mathrm{~mm}$. The cylinder rock sample with height of $100 \mathrm{~mm}$ and diameter of $50 \mathrm{~mm}$ is used to carry out the uniaxial compression test on MTS815.02 testing system. The rock sample's parameters are shown in Table 1. The experimental parameters used are presented in Table 2. 

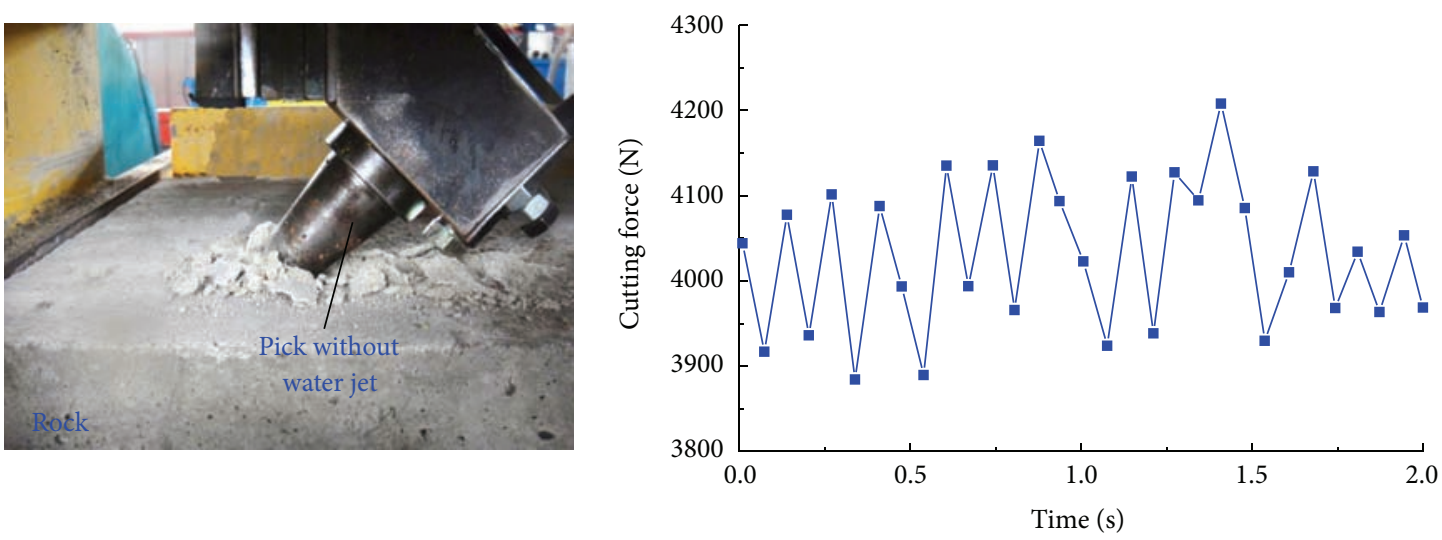

FIGURE 6: Photo of cutting experiment and cutting force for pick without water jet.

TABLE 2: Experimental parameters.

\begin{tabular}{lccccc}
\hline Parameter & \multicolumn{5}{c}{ Value } \\
\hline Jet pressure $(\mathrm{MPa})$ & 0 & 10 & 20 & 30 & 40 \\
Cutting tool & JFP & JRP & Combined & & \\
Cutting depth $(\mathrm{mm})$ & & & 10 & & \\
Cutting speed $(\mathrm{m} / \mathrm{s})$ & & & 0.2 & & \\
Cutting angle $\left({ }^{\circ}\right)$ & & & 45 & & \\
\hline
\end{tabular}

\section{Results and Discussions}

In order to compare the effect of different configuration modes, the rock breaking experiment without water jet assistance is carried out firstly. The cutting speed is $0.2 \mathrm{~m} / \mathrm{s}$ and the cutting depth is $10 \mathrm{~mm}$. Figure 6 shows the photo of cutting experiment and the cutting force of the pick without water jet. The mean cutting force without water jet is $4051 \mathrm{~N}$. The variance is $5713 \mathrm{~N}^{2}$.

The experiment assisted with high pressure water jet is conducted, the cutting angle is $45^{\circ}$, and the cutting depth is $10 \mathrm{~mm}$. The target distance and the distance between the pick tip and the attack point are $25 \mathrm{~mm}$ and $5 \mathrm{~mm}$. The experiment is carried out under the water pressure of $10 \mathrm{MPa}$, $20 \mathrm{MPa}, 30 \mathrm{MPa}$, and $40 \mathrm{MPa}$. Figure 7 shows the photos of cutting experiment and the cutting force of JFP and new typed JRP.

The photos in Figure 7 show the picks cutting rock with the assistance of JFP and new typed JRP. The simplified cutting force curves were obtained by filtering the cutting force data tested from pressure sensor. It can be seen that the force value fluctuates around the average and the mean cutting forces of JFP and the new typed JRP decrease with the water jet pressure. To observe the assistance effect of front and rare water jet directly, the force decrease rate was introduced as $\eta=\left(F_{p}-F_{w}\right) / F_{p}$, where $F_{p}$ is the cutting force of a common pick and $F_{w}$ is the cutting force of pick assisted with water jet. The force statistics decrease rates of JFP and new typed JRP are shown in Figure 8. Moreover, the variance of the cutting force was taken statistics to study the influence of JFP and new typed JRP on fluctuation of cutting force, shown in Figure 9.
Figure 8 shows that the force decrease rates of JFP and the new typed JRP increase with the water jet pressure. However, the new typed JRP is less effective than the JFP. When the water pressure is $40 \mathrm{MPa}$, the reduction rate of the cutting force is only $1.86 \%$ while it is $10.97 \%$ for JFP. The reason is that, firstly, the pick cuts into the rock with an angle (cutting angle), and the jet attack point is far from the pick tip with the influence of the pick holder's shape; the cracks mainly exist in front of pick tip; thus the water jet is hard to go directly into the cracks to extend them further. Secondly, in order to avoid the direct crash between rear nozzle and the rock, the rear jet target distance is large; when the high pressure water erupts, the pressure reduces rapidly, which does not make the best use of the water jet's impact ability.

It should be noted that there is a threshold pressure for the effect of front water jet assistance, and the threshold pressure is about two or two times greater than the coal sample's compression strength. In the above experiment the threshold pressure is around $20-30 \mathrm{MPa}$. When the water pressure is lower than the threshold pressure, the assistance effect is not obvious, and the force reduction rate is generally lower than $5 \%$. For the front water jet, when the water pressure is lower than $20 \mathrm{MPa}$, the cutting force even increases. It indicates that, at low pressure, the front water jet cannot timely crush the rock. Instead, a layer of pressure water film is formed on the surface of the rock, which will prevent the rock from caving. In this case, the pick tip's cutting impact cannot perform to the best of its abilities. Moreover, when the water pressure is higher than the threshold pressure, the front jet works better. When the water pressure is up to $40 \mathrm{MPa}$, the cutting force reduces by $10.97 \%$.

From Figure 9, the variance of cutting force decreases with the water jet pressure generally for both JFP and the new typed JRP. And compared with the new typed JRP, the variance of JFP is smaller. When the water pressure is lower than the threshold pressure, the decrease of load fluctuation is not obvious. It indicates that, at the low pressure area, the water jet mainly plays a role of humidification. The water weakens the rock's frangibility. While the water pressure is higher than the threshold pressure, the water pressure can fully damage the rock and reduce the load fluctuation significantly. 

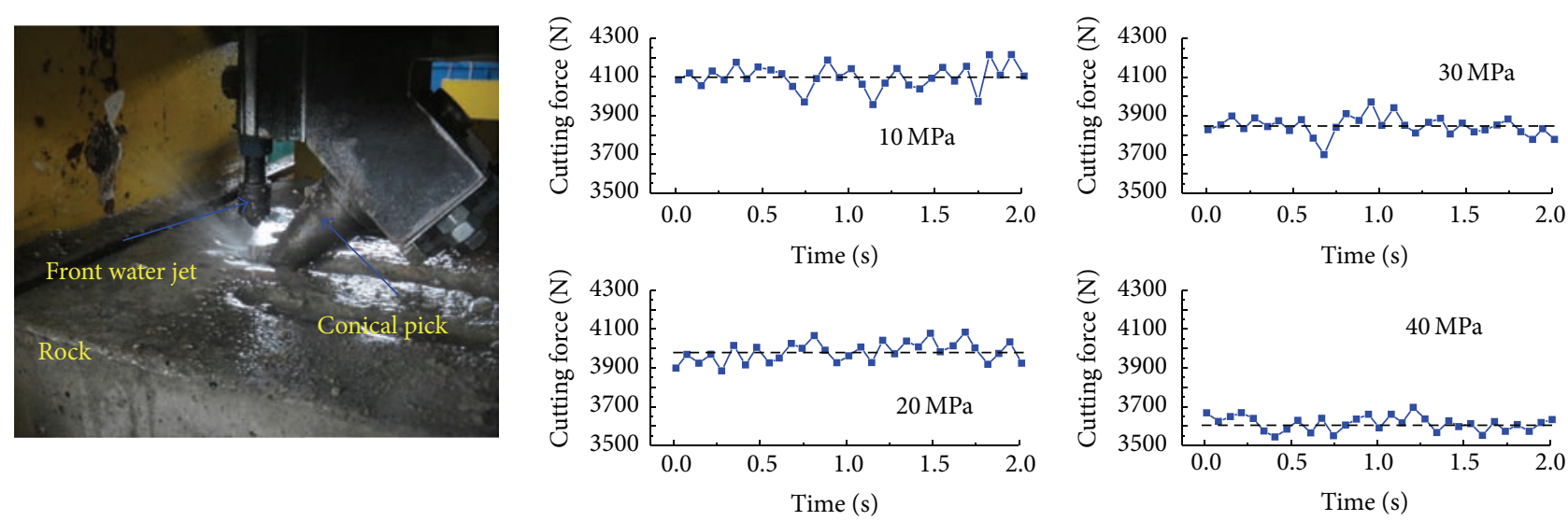

(a) JFP
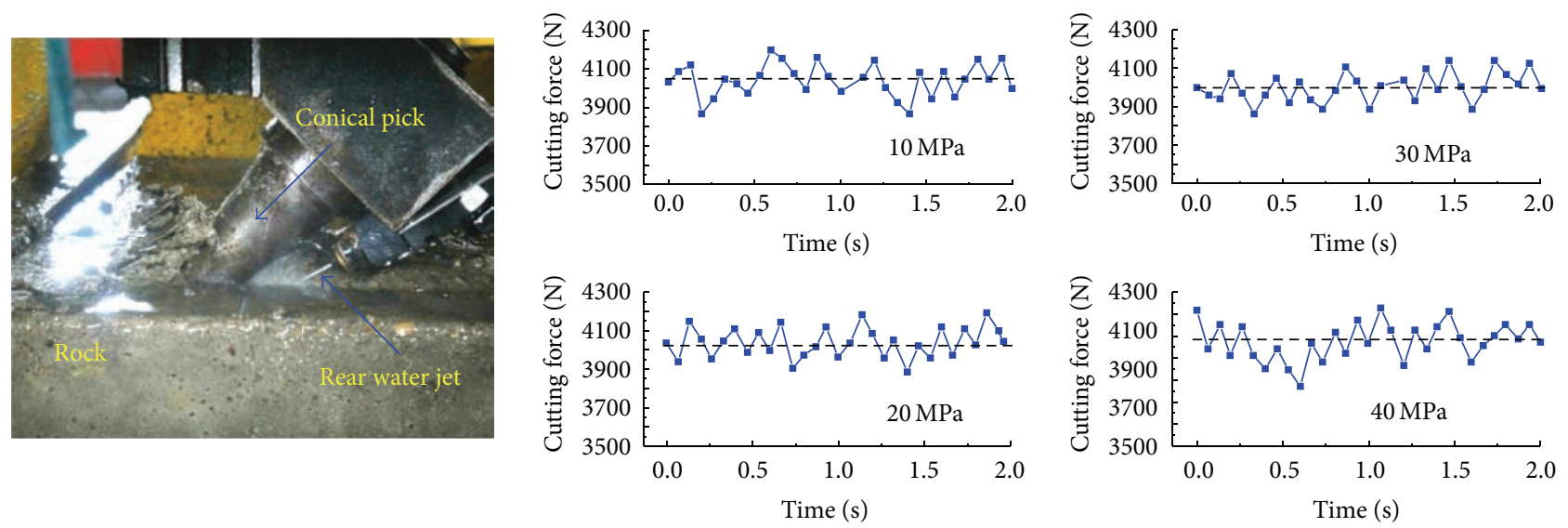

(b) New typed JRP

FIGURE 7: Photos of cutting experiment for JFP and new typed JRP.

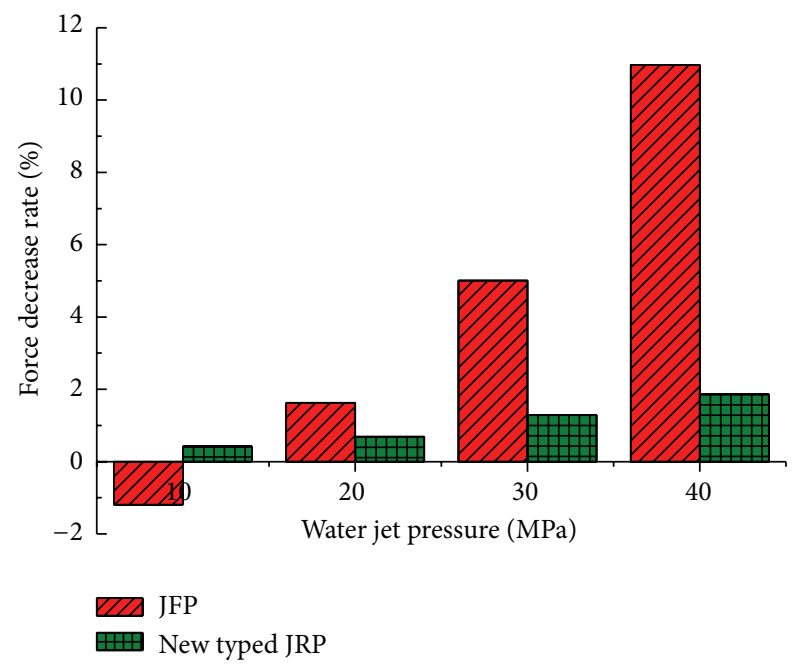

Figure 8: Cutting force decrease rates.

It should be pointed out that though the assistance effect of rear water jet is not obvious, there are less rock fragmentations behind the pick, so the high pressure water

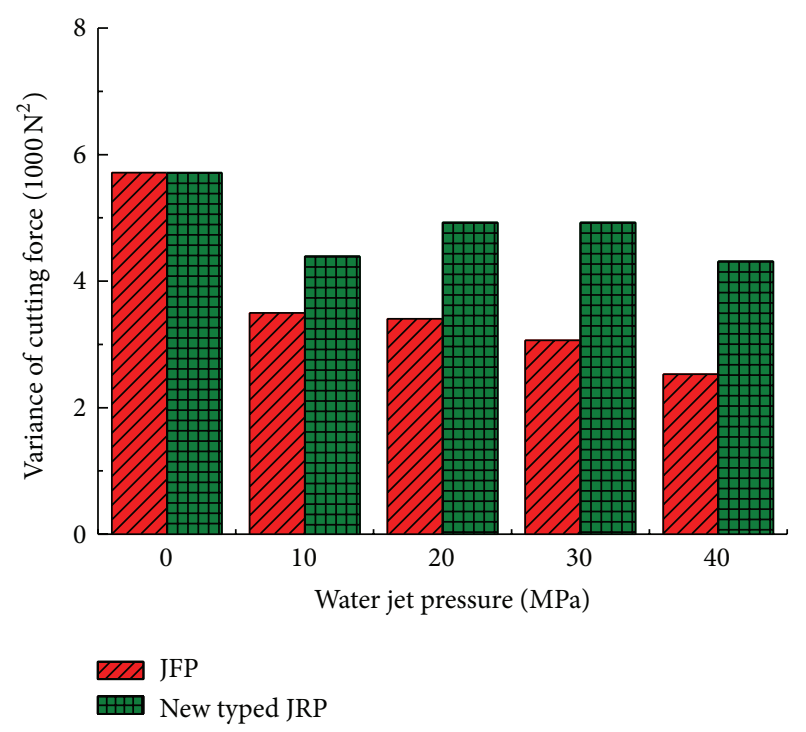

FIGURE 9: Variance of the cutting force.

can directly attack the groove to make the cracks extend further. Figure 10(a) shows the groove formed by front water jet of $30 \mathrm{MPa}$, while Figure 10(b) shows the one formed by 


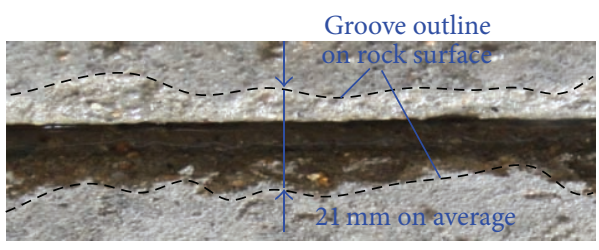

(a) JFP of $30 \mathrm{MPa}$

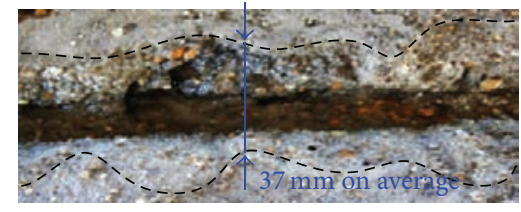

(b) New typed JRP of $30 \mathrm{MPa}$

FIgURE 10: Grooves formed in the cutting process.

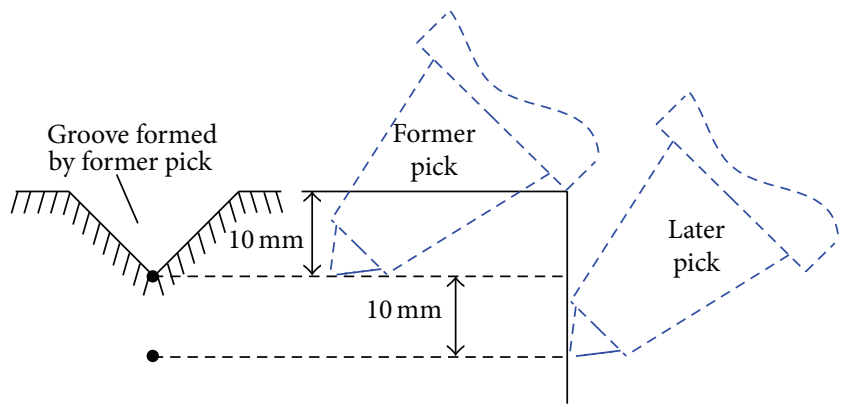

FIGURE 11: Cutting condition of later pick.

rear water jet of $30 \mathrm{MPa}$. It can be seen that the groove shape in Figure 10(a) is relatively flat, while the one in Figure 10(b) is broken severely. The broken grooves make preparations for the later cutting. Therefore, the further cutting experiment is necessary to be carried out to explore the influence of groove on rock breaking performance of the later pick.

In order to study the rock breaking performance of the later pick, the further cutting experiment is carried out in the broken groove formed by the $0 \mathrm{MPa}, 10 \mathrm{MPa}, 20 \mathrm{MPa}$, $30 \mathrm{MPa}$, and $40 \mathrm{MPa}$ rear water jet. The cutting depth is $10 \mathrm{~mm}$, shown in Figure 11.

The force statistics decrease rates of the later pick are shown in Figure 12. Moreover, the variance of the cutting force was taken statistics to study the influence of JFP and new typed JRP on fluctuation of cutting force, shown in Figure 13.

Compared with Figure 8, the variation trend and magnitude of the cutting force decrease rate for JFP almost remain the same, while those for new typed JRP increase under different water jet pressure, and the variation trend and magnitude are almost the same as those of JFP. This indicates that there is no difference in influence of the two water jet configuration modes on cutting force decrease rate in the following cutting. Even so, from the experiments data, the new typed JRP is more effective on decreasing cutting force.

Compared with Figure 9, variance of the cutting force in Figure 13, for both JFP and new typed JRP, increases to some degree, which results from the increased interference between rock and cutting pick. But the variation trend and magnitude of variance for JFP almost remain the same; while variation trend for new typed JRP is almost the same as that of JFP, however, the magnitude is larger than that for JFP.

From the analysis above, there is no great difference in influence of the two water jet configuration modes on rock

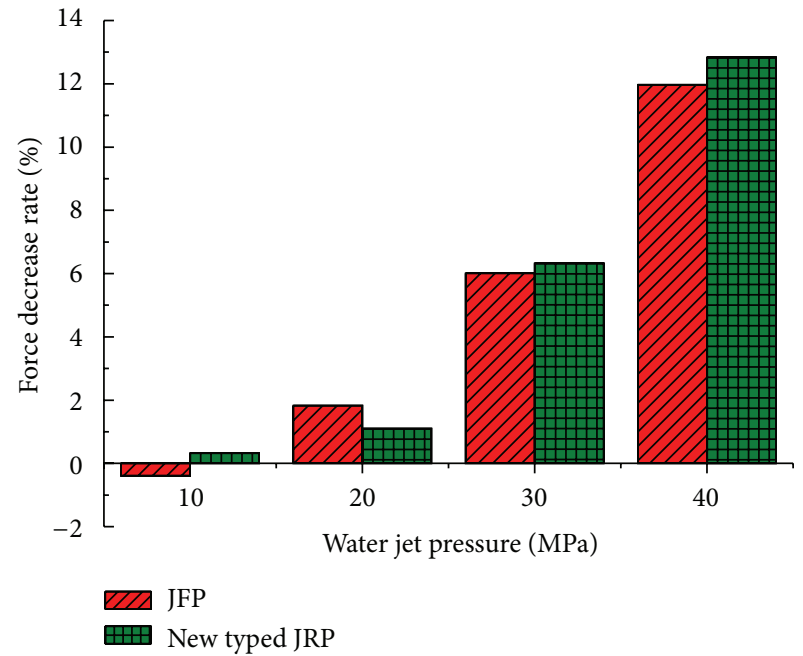

FIGURE 12: Cutting force decrease rates for later pick.

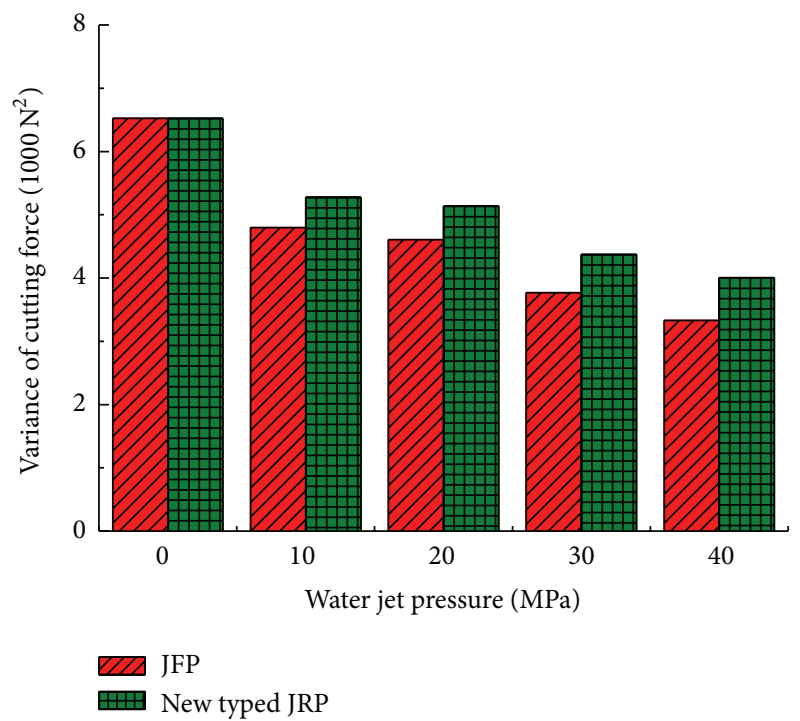

FIGURE 13: Variance of the cutting force for later pick.

breaking performance. But each has its own advantages; for example, the new typed JRP is more effective on decreasing cutting force and JFP is more effective on decreasing force fluctuation.

Based on the study above, the experiment with combined water jet assistance is conducted to study the rock breaking 


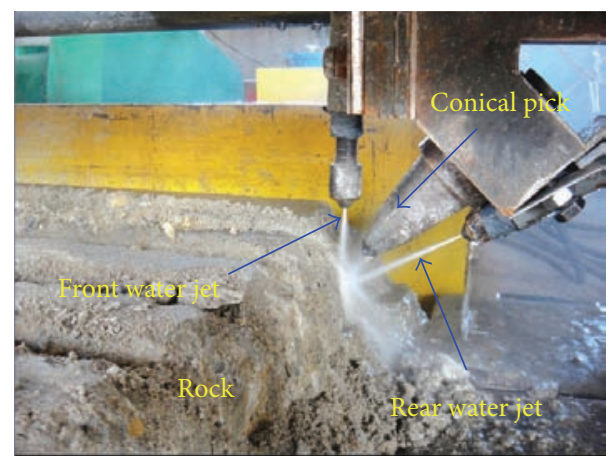

FIGURE 14: Photo of cutting experiment for JFRP.

performance. The combination of those two water jet configuration modes (JFRP) is processed as shown in Figure 14. The experiment conditions are the same as the experiments above. The force statistics decrease rates of the combined pick are shown in Figure 15. Moreover, the variance of the cutting force was taken statistics, shown in Figure 16.

Figures 15 and 16 show that the combination of those two water jet configuration modes (JFRP) is effective for rock breaking. It can both decrease the cutting force and lower down the fluctuation. Compared with that for single water jet configuration, the variation trend of the cutting force decrease rate for the combined one remains the same, but the magnitude increases under different water jet pressure. When the water pressure is up to $40 \mathrm{MPa}$, the cutting force decreases by $15.06 \%$ and the later pick's cutting force can reduce by $16.26 \%$. Under the combined water jet configuration, the cutting force variance decreases significantly, showing that the combined way is helpful to decrease the load fluctuation. This is positive to enhance the picks work stability and prolong the relative parts' service life. But it is important to note that the effect of the combined water jet configuration is not that of the direct adding of JFP and new typed JRP. The injecting off distance increases and the assistance ability decreases when a layer of rock was broken by water jet. At this time, the rock breaking performance will not be enhanced, though the pick is assisted with the combination of those two water jet configuration modes. Thus, the combined water jet should not be applied due to much water and energy waste.

\section{Conclusions}

(1) The force decrease rates of JFP and the new typed JRP increase with the water jet pressure. However, the new typed JRP is less effective than the JFP. When the water pressure is $40 \mathrm{MPa}$, the reduction rate of the cutting force is only $1.86 \%$, while it is $10.97 \%$ for JFP.

(2) The variance of cutting force decreases with the water jet pressure generally for both JFP and the new typed JRP. And compared with the new typed JRP, the variance of JFP is smaller.

(3) For the later pick, there is no great difference in influence of the two water jet configuration modes on rock breaking performance. But each has its own

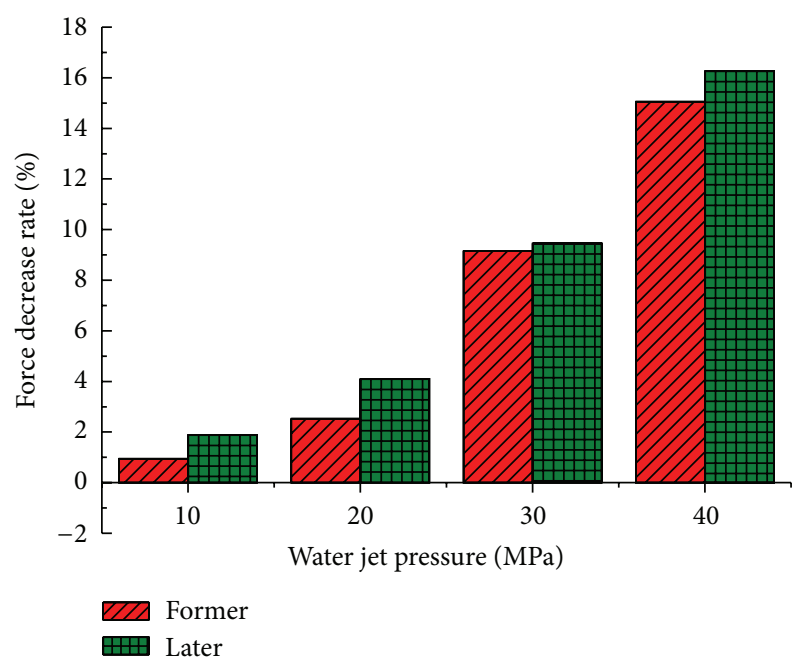

FIgURE 15: Cutting force decrease rates for combined pick.

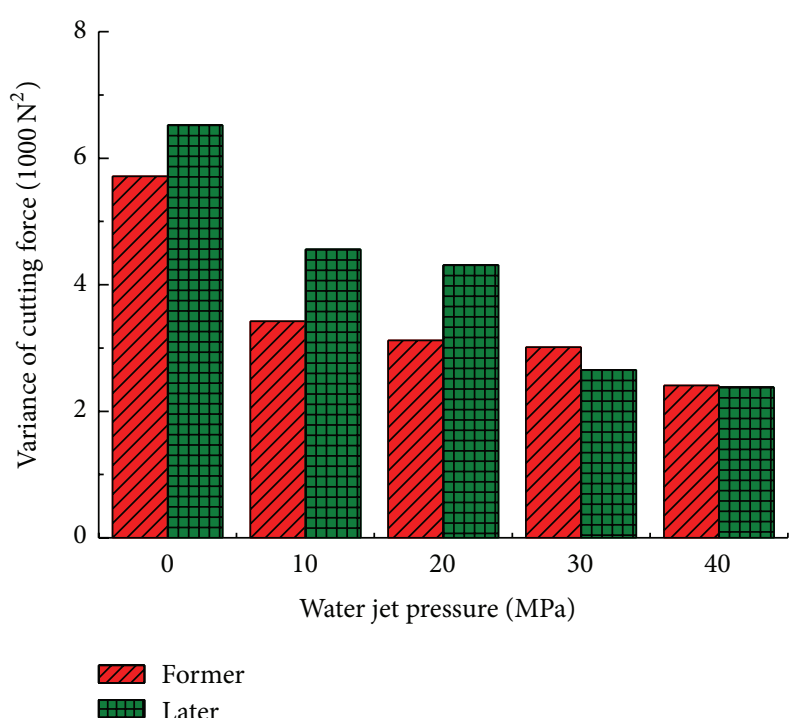

Figure 16: Variance of the cutting force for combined pick.

advantages; for example, the new typed JRP is more effective on decreasing cutting force and JFP is more effective on decreasing force fluctuation.

(4) The combination of those two water jet configuration modes (JFRP) is effective for rock breaking. It can both decrease the cutting force and lower down the fluctuation. Compared with that for single water jet configuration, the variation trend of the cutting force decrease rate for the combined one remains the same, but the magnitude increases under different water jet pressure. When the water pressure is up to $40 \mathrm{MPa}$, the cutting force decreases by $15.06 \%$ and the later pick's cutting force can reduce by $16.26 \%$. However, the effect of the combined water jet configuration is not that of the direct adding of JFP and new typed JRP. Thus, the combined water jet should not be applied due to much water and energy waste. 


\section{Conflict of Interests}

The authors declare that there is no conflict of interests regarding the publication of this paper.

\section{Acknowledgments}

This project is supported by Special Foundation for Excellence Nurturing Engineering of China University of Mining and Technology (2015YC03) and the Priority Academic Program Development of Jiangsu High Education Institute of China.

\section{References}

[1] N. Bilgin, M. A. Demircin, H. Copur, C. Balci, H. Tuncdemir, and N. Akcin, "Dominant rock properties affecting the performance of conical picks and the comparison of some experimental and theoretical results," International Journal of Rock Mechanics \& Mining Sciences, vol. 43, no. 1, pp. 139-156, 2006.

[2] S.-Y. Liu, C.-L. Du, and X.-X. Cui, "Research on the cutting force of a pick," Mining Science and Technology, vol. 19, no. 4, pp. 514517, 2009.

[3] X. H. Liu, S. Y. Liu, X. X. Cui, and P. Tang, "Interference model of conical pick in cutting process," Journal of Vibroengineering, vol. 16, no. 1, pp. 115-128, 2014.

[4] R. M. Goktan and N. Gunes, "A semi-empirical approach to cutting force prediction for point-attack picks," Journal of The South African Institute of Mining and Metallurgy, vol. 105, no. 4, pp. 257-263, 2005.

[5] O. Su and N. A. Akcin, "Numerical simulation of rock cutting using the discrete element method," International Journal of Rock Mechanics and Mining Sciences, vol. 48, no. 3, pp. 434-442, 2011.

[6] J. Rojek, E. Oñate, C. Labra, and H. Kargl, "Discrete element simulation of rock cutting," International Journal of Rock Mechanics \& Mining Sciences, vol. 48, no. 6, pp. 996-1010, 2011.

[7] M. Z. A. Bakar and L. S. Gertsch, "Evaluation of saturation effects on drag pick cutting of a brittle sandstone from full scale linear cutting tests," Tunnelling and Underground Space Technology, vol. 34, pp. 124-134, 2013.

[8] G. van Wyk, D. N. J. Els, G. Akdogan, S. M. Bradshaw, and N. Sacks, "Discrete element simulation of tribological interactions in rock cutting," International Journal of Rock Mechanics \& Mining Sciences, vol. 65, pp. 8-19, 2014.

[9] O. Fenn, "The use of water jets to assist free-rolling cutters in the excavation of hard rock," Tunnelling and Underground Space Technology, vol. 4, no. 3, pp. 409-417, 1989.

[10] R. Ciccu and B. Grosso, "Improvement of the excavation performance of PCD drag tools by water jet assistance," Rock Mechanics and Rock Engineering, vol. 43, no. 4, pp. 465-474, 2010.

[11] R. Ciccu and B. Grosso, "Improvement of disc cutter performance by water jet assistance," Rock Mechanics and Rock Engineering, vol. 47, no. 2, pp. 733-744, 2014.

[12] Y. Ozcelik, R. Ciccu, and G. Costa, "Comparison of the water jet and some traditional stone surface treatment methods in different lithotypes," Construction and Building Materials, vol. 25, no. 2, pp. 678-687, 2011.

[13] Y. Ozcelik, A. E. Tercan, E. Yilmazkaya, R. Ciccu, and G. Costa, "A Study of nozzle angle in stone surface treatment with water jets," Construction and Building Materials, vol. 25, no. 11, pp. 4271-4278, 2011.

[14] V. Sharma, S. Chattopadhyaya, and S. Hloch, "Multi response optimization of process parameters based on Taguchi-Fuzzy model for coal cutting by water jet technology," International Journal of Advanced Manufacturing Technology, vol. 56, no. 912, pp. 1019-1025, 2011.

[15] X. F. Yang, X. H. Li, and Y. Y. Lu, "Wear characteristics of the cemented carbide blades in drilling limestone with water jet," International Journal of Refractory Metals and Hard Materials, vol. 29, no. 2, pp. 320-325, 2011.

[16] S. Dehkhoda and M. Hood, "An experimental study of surface and sub-surface damage in pulsed water-jet breakage of rocks," International Journal of Rock Mechanics \& Mining Sciences, vol. 63, pp. 138-147, 2013.

[17] S. Dehkhoda and M. Hood, "The internal failure of rock samples subjected to pulsed water jet impacts," International Journal of Rock Mechanics \& Mining Sciences, vol. 66, pp. 91-96, 2014.

[18] R. Gryc, L. M. Hlaváč, M. Mikoláš, J. Šancer, and T. Daněk, "Correlation of pure and abrasive water jet cutting of rocks," International Journal of Rock Mechanics and Mining Sciences, vol. 65, pp. 149-152, 2014.

[19] G. Aydin, "Recycling of abrasives in abrasive water jet cutting with different types of granite," Arabian Journal of Geosciences, vol. 7, no. 10, pp. 4425-4435, 2014.

[20] Y. Y. Lu, J. R. Tang, Z. L. Ge, B. W. Xia, and Y. Liu, "Hard rock drilling technique with abrasive water jet assistance," International Journal of Rock Mechanics \& Mining Sciences, vol. 60, pp. 47-56, 2013.

[21] G. Y. Peng and S. J. Shimizu, "Progress in numerical simulation of cavitating water jets," Journal of Hydrodynamics, vol. 25, no. 4, pp. 502-509, 2013.

[22] D. Z. Song, E. Y. Wang, Z. T. Liu, X. F. Liu, and R. X. Shen, "Numerical simulation of rock-burst relief and prevention by water-jet cutting," International Journal of Rock Mechanics \& Mining Sciences, vol. 70, pp. 318-331, 2014.

[23] S. Y. Liu, Z. H. Liu, X. X. Cui, and H. Jiang, "Rock breaking of conical cutter with assistance of front and rear water jet," Tunnelling and Underground Space Technology, vol. 42, pp. 7886, 2014.

[24] L. Songyong, C. Junfeng, and L. Xiaohui, "Rock breaking by conical pick assisted with high pressure water jet," Advances in Mechanical Engineering, vol. 6, Article ID 868041, 2014.

[25] S. Y. Liu, X. H. Liu, J. F. Chen, and M. X. Lin, "Rock breaking performance of a pick assisted by high-pressure water jet under different configuration modes," Chinese Journal of Mechanical Engineering, vol. 28, no. 3, pp. 607-617, 2015.

[26] X. Liu, S. Liu, and P. Tang, "Coal fragment size model in cutting process," Powder Technology, vol. 272, pp. 282-289, 2015. 

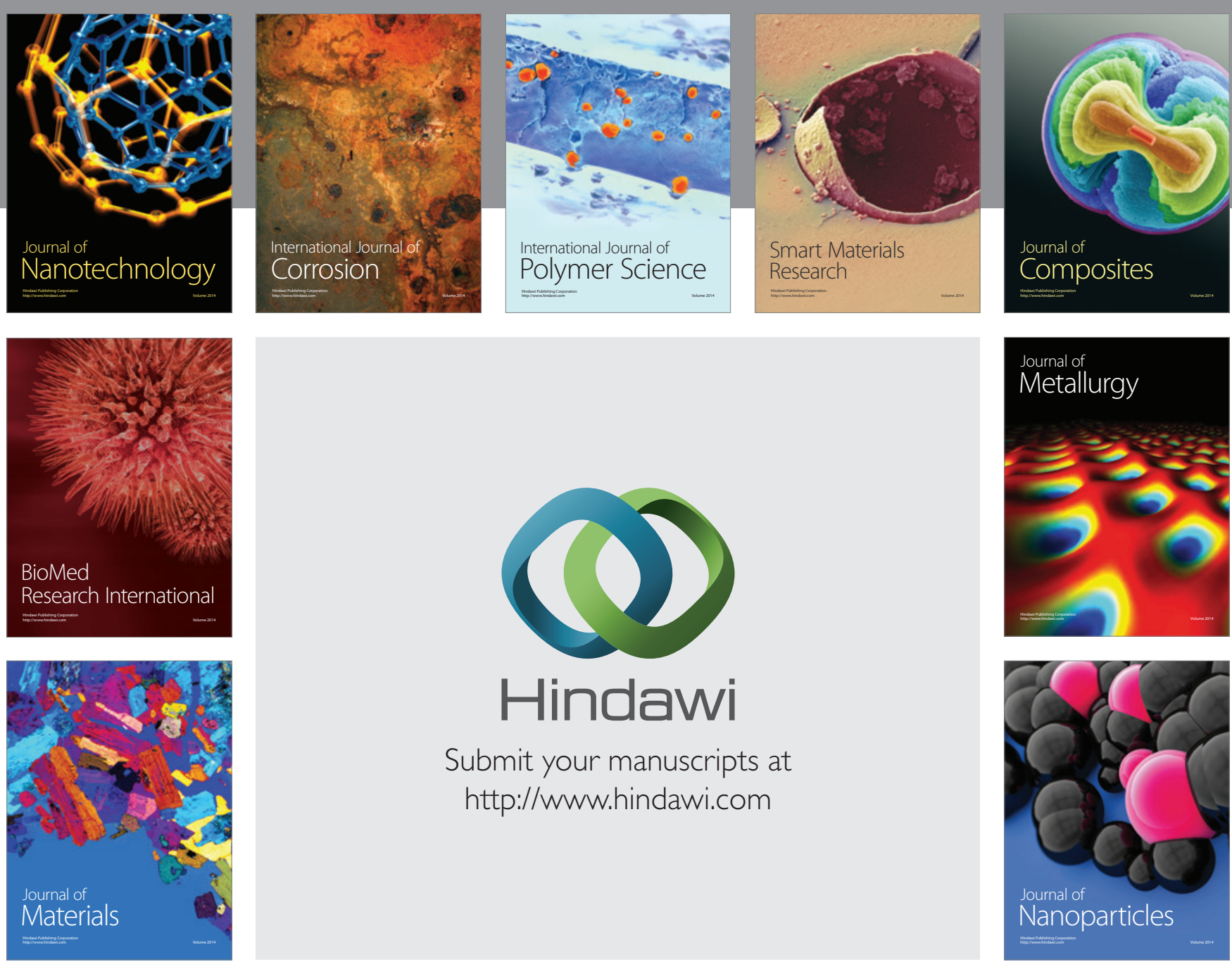

Submit your manuscripts at http://www.hindawi.com
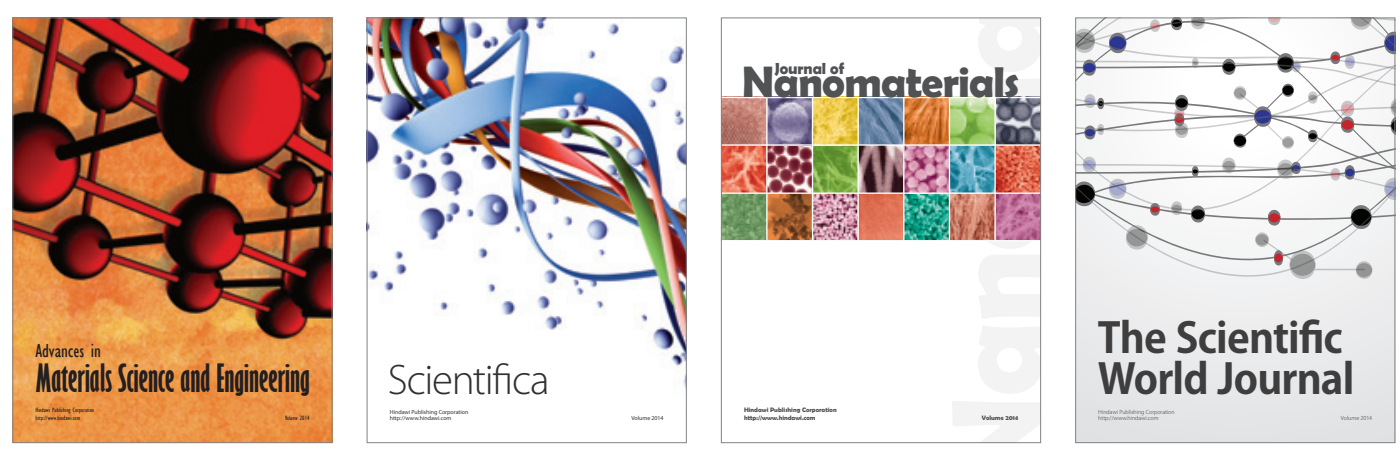

\section{The Scientific World Journal}
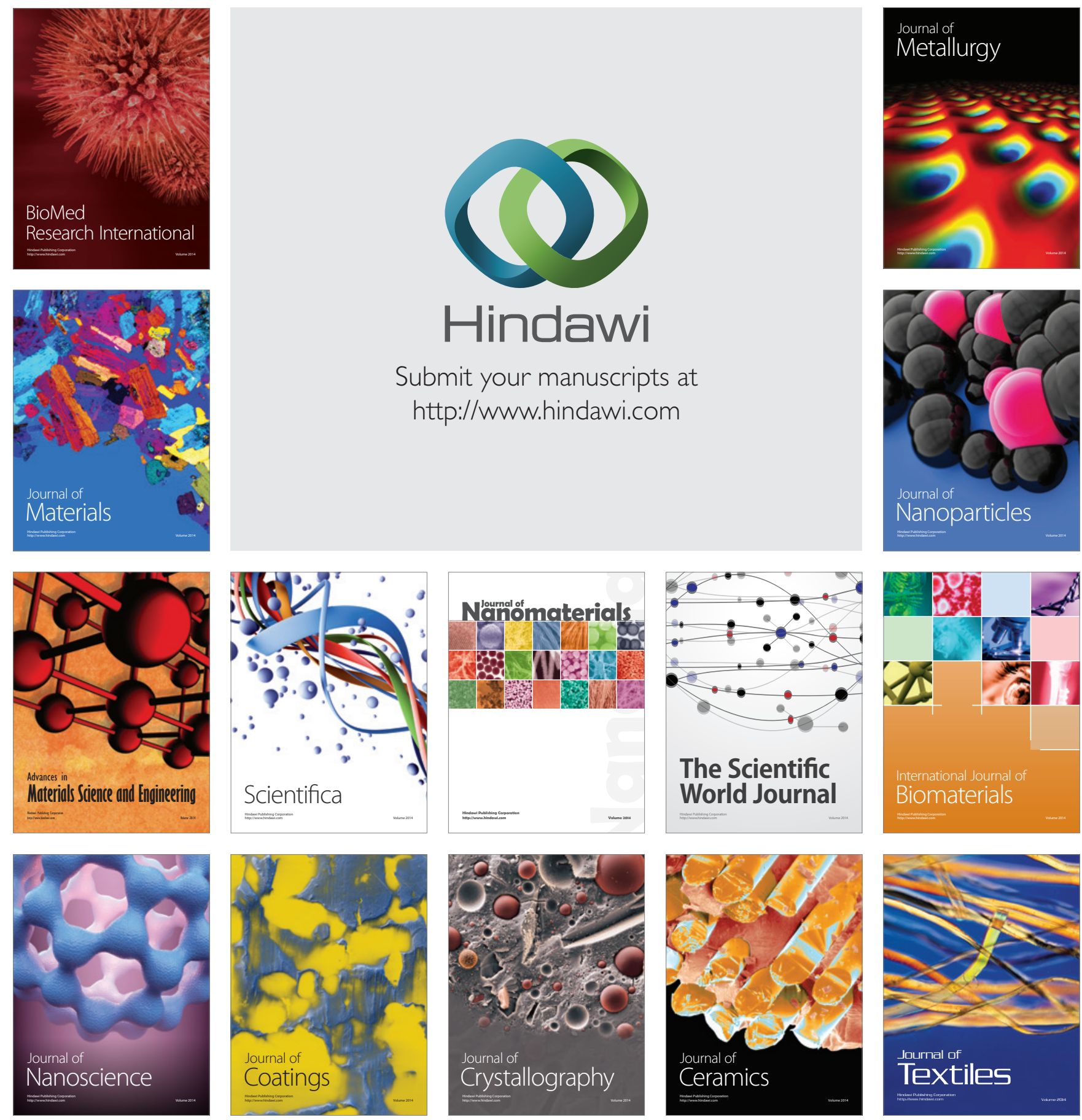